\title{
Epidemiological Aspects of Pathogenic Microbial Foodborne Disease Outbreaks in Korea and Japan, 1999-2004
}

\author{
Hyeong Ae Bang $\cdot$ Myeong Jin Lee* Y Young Hwan Kim*** \\ Won Chang Lee***-Kook Hwan Rhim**† \\ Faculty of Public Health, The Korean Public Health Association \\ *Department of Public Health, Kobe University Graduate School of Medicine, Kobe, Japan \\ **College of Health Sciences, Korea University \\ ***College of Veterinary Medicine, Konkuk University \\ (Received May 14, 2007/Accepted May 30, 2007)
}

\begin{abstract}
Pathogenic microbial foodborne disease outbreaks (PMFBDOs) have increased in many countries, the boom in food service establishment is not matched by effective food safety and control. In this study, we investigated the current state and the epidemic aspects of FBDOs in Korea and Japan. In Korea, the average prevalence rate of foodborne disease (FBD) was 15.0 per 100,000 population and cases per outbreak of FBD was 57.0. During the same period in Japan, the prevalence rate showed an average of 24.9, and the cases per outbreak were 16. When both prevalence rate and cases per outbreak were compared, the prevalence rate in Japan was much higher than that in Korea $(p<0.01)$. However, average cases per outbreak of FBD in Japan were much lower than those in Korea $(p<0.01)$. In Korea, outbreaks of FBDs were more common in spring $(p<0.01)$, while in Japan, more frequent in summer and winter $(\mathrm{p}<0.01)$. Outbreaks of FBD occurred largely through restaurant and school foods $(32.0 \%$ and $27.5 \%)$ in Korea. In Japan, the proportion of the outbreak cases in the restaurant and home were $23.7 \%$ and $12.1 \%$, and cases of unknown causes of FBDs were $48.2 \%$, respectively. Bacteria were the major causes of infection in both countries. The prevalence of PMFBDOs by Salmonella spp. Vibrio parahemolyticus and Staphylococcus aureus were much higher in Korea, while those by Camphylobacter spp. and SRSV were more common in Japan. The causes by virus were more frequent in Japan (13.7\%) than in Korea $(7.7 \%)$. The prevalence of FBDs in Korea and Japan showed characteristic differences, especially in the PMFBDOs due to such factors as geography, climate, culture, diet and food management.
\end{abstract}

Keywords: foodborne disease, Korea, Japan, prevalence, risk factors

\section{Introduction}

Foodborne Disease (FBD) are defined as diseases, usually either infectious or toxic in nature, caused by agents that enter the body through the ingestion of food. Every person is at risk of FBD. ${ }^{1)}$ Some FBD are well recognized, but are considered emerging because they have recently become more common. ${ }^{2)}$ FBDs are a widespread and growing public health problem, both in development and developing countries. ${ }^{1)}$ The global importance of food safety is not fully appreciated by many public health authorities despite the constant increase in the prevalence of FBDs. ${ }^{3,4)}$ Significant changes in the life-styles of developing countries have taken

\footnotetext{
${ }^{\dagger}$ Corresponding author : College of Health Sciences,

Korea University

Tel. 011-287-9998, Fax. 82-2-909-0064

E-mail : khim69@korea.ac.kr
}

place during the past decade, especially in food preparing facility and industry as well as safety. The surveillance for FBD has been stressed because of centralization of food production and increased international trade and tourism. ${ }^{2,5)}$ The responsibility for food safety has moved from individuals to industries and government, thereby these changes have created potentials for epidemiological outbreaks of FBD.

Korea and Japan are situated very close to each other geographically, and as well as they share similarities in several aspects such as foods, climate, life style and social system, etc.

Our intention was to study current trends of foodborne disease outbreaks (FBDOs), including pathogenic microbial foodborne disease outbreaks (PMFBDOs) in Korea and Japan for the six-years period from 1999 to 2004 by considering prevalence and risk factors of FBD in conjunction with the main pathogenic substances. 


\section{Material and Methods}

\section{Data Collection/Aims}

Detailed in data collection were previously report. ${ }^{5)}$ Based on the surveillance data of FBDOs, most of the confirmed cases in Korea obtained from "Outbreak Food Poisoning (Web), 19992004" by Korea Food and Drug Administration (KFDA), ${ }^{6}$ and "Status of Food Poisoning Outbreaks", 1999-2004 by KFDA.7 Japanese data were obtained from "Topics; Food Safety Information: Annual Report of Food Poisoning Outbreaks (Web), 19992004" by Ministry of Health, Labour and Welfare, Japan (MHLWJ), and "Statistics of Food Poisoning Japan" published by Inspection and Safety Division, Department of Food Sanitation, MHLWJ from 1999 to $2004 .^{9)}$

To better quantify the impact of FBDOs on health in Korea and Japan, we complied and analyzed information from multiple surveillance system and other source for six years period from 1999 to 2004 by considering prevalence and relation to risk factors including prevalence rate of FBDs, cases per outbreak, seasonal outbreaks, outbreaks of venues, causative agents (pathogenic microorganisms) and others.

\section{Data Analysis}

Statistical methods of data analysis used included one-way analysis of variance (ANOVA) for the prevalence rate per 100,000 of FBDs, and cases per outbreak between Korea and Japan during period from 1999 to 2004. Another data analysis was performed using Microsoft Excel with a Chi-square test $\left(\mathrm{X}^{2}\right.$-test $)$ to compare the frequency distribution in the rate of FBDs with the FBDOs of seasonal, venues of facilities and pathogenic substances. In addition, calculated with $95 \%$ confidence intervals of the rate of case frequency. Result were considered to significant at $\mathrm{p}<0.05$ and $\mathrm{p}<0.01$.

\section{Results}

\section{Prevalence of Foodborne Disease Outbreaks and Relative Risk Factors}

Table 1 shows the prevalence and relative risk factors of FBDs between Korea and Japan from 1999 to 2004. In Korea, the average prevalence
Table 1. Comparative observation of the relative risk of foodborne disease outbreaks between Korea and Japan, 1999-2004

\begin{tabular}{lcc}
\hline \multicolumn{1}{c}{ Index } & KOREA & JAPAN \\
\hline Prevalence rate & 15.0 & $24.9^{* *}$ \\
No. of Cases & 42,716 & 189,542 \\
No. of Outbreaks & 749 & 11,973 \\
Cases/Outbreak & $57^{* *}$ & 16 \\
Seasonal outbreaks & & \\
$\quad$ Spring & $256(34.2)^{* *}$ & $2,061(17.2)$ \\
$\quad$ Summer & $263(35.1)$ & $4,648(38.8)^{*}$ \\
$\quad$ Autumn & $196(26.2)$ & $3,185(26.6)$ \\
$\quad$ Winter & $34(4.5)$ & $2,079(17.4)^{* *}$ \\
$\quad$ Sum & 749 & 11,973 \\
Identified of Causes & & \\
$\quad$ Microbe; & & \\
$\quad$ Bacteria & $412(55.0)$ & $9.247(77.2)^{* *}$ \\
$\quad$ Virus & $34(4.5)$ & $1,461(12.2)^{* *}$ \\
$\quad$ Sum & $446(59.5)$ & $10,708(89.4)$ \\
Others Causes & $303(40.5)^{* *}$ & $1,265(10.6)$ \\
Total & 749 & 11,973 \\
\hline R
\end{tabular}

Remarks; Prevalence rate per 100,000 population (compared by one-way ANOVA) Chi-squared analysis indicated a significant difference from the total value, ${ }^{*} \mathrm{p}<0.05, * * \mathrm{p}<0.01$. \# 95\% CI; Confidence interval of $95 \%$ of the rate.

rate of FBDs was 15.0 per 100,000 population with a variation from 6.26 to 21.6 , and cases per outbreak (Cases/Outbreaks) of FBD was 57.0. During the same period in Japan, the prevalence rate showed an average of 24.9 with a variation from 20.3 to 34.2 , and the cases per outbreak was 16. When both prevalence rate and cases per outbreak were compared, the prevalence rate in Japan was much higher than in Korea (ANOVA; $\mathrm{p}<0.01$ ). However, average cases per outbreaks of FBD in Japan was much lower than that in Korea (ANOVA; $\mathrm{p}<0.01$ ).

The seasonal distribution of FBDs outbreaks throughout a year showed that the prevalence in spring were in Korea than that in Japan $\left(\mathrm{X}^{2}\right.$-test; $\mathrm{p}<0.01)$, and the incidence in summer and winter were more in Japan than Korea $\left(\mathrm{X}^{2}\right.$-test; $\left.\mathrm{p}<0.01\right)$ (Table 1). 
In order to find what the major causes of FBD in Korea and Japan, we compared the data from 1999 to 2004. In Korea, $55.0 \%$ (412 cases) of total 749 outbreaks of FBD was due to bacteria, $4.5 \%$ (34 cases) was owing to virus, and $40.5 \%$ (303 cases) was caused by other pathogenic substances (chemicals etc.) including unknown cases. In Japan, $77.2 \%$ ( 10,708 cases) of total 11,973 outbreaks of FBD was due to bacteria, $12.2 \%$ (1,461 cases) was owing to virus, and $10.6 \%$ (1,265 cases) was caused by others including unknown cases. Taken together, the prevalence of FBD caused by the bacteria and virus was higher in Japan than in Korea ( $\mathrm{X}^{2}$-teast; $\mathrm{p}<0.01$ ), while the prevalence caused by other agents was lower in Japan than Korea $\left(\mathrm{X}^{2}\right.$-test; $\left.\mathrm{p}<0.01\right)$.

\section{The Venues of FBDOs}

Table 2 shows the venues of facilities where the outbreaks of FBDs from 1999 to 2004. In Korea, approximately a third a FBD outbreaks cases $(32.0 \%)$ occurred at restaurants. The rest of the outbreak of FBD at schools $(27.5 \%)$, homes $(8.6 \%)$, work-place $(7.6 \%)$, hotels $(0.9 \%)$, others including food stores $(21.2 \%)$ and unknown places $(2.1 \%)$. In Japan, the Major places of venues were restaurants $(23.7 \%)$, homes $(12.1 \%)$, hotels $(5.3 \%)$ work-places $(2.9 \%)$, schools $(1.3 \%)$, others including food stores $(6.5 \%)$ and unknown facilities $(48.2 \%)$. FBDs outbreaks were frequently occurred via restaurant and school foods in Korea, while via unknown venues, restaurants and homes in Japan
$\left(\mathrm{X}^{2}\right.$-test; $\left.\mathrm{p}<0.01\right)$

\section{Microorganisms Responsible for PMFBDOs}

As shown in Table 3, bacteria were the most common implication pathogenic microorganisms causing FBDs in Korea. The number of bacterial FBDs were 412 of 446 cases of total PMFBDOs (92.5\%), which had etiologic related to Salmonella species (spp.) (33.9\%), Vibrio parahemolyticus (27.1\%), Staphylococcus aureus (13.9\%), Escherichia coli (7.5\%), Bacillus cereus (1.3\%), Campylobacter spp. (1.3\%), Enterohemorrhagic E. coli $(1.1 \%)$, and other bacterial spp. (6.3\%). The FBDOs by virus were only 31 (7.7\%): Norovirus $(5.4 \%)$, Small round structure virus (SRVS) $(1.1 \%)$, Calicivirus (0.7\%), and Astrovirus $(0.5 \%)$, respectively.

In Japan, 9,247 cases $(86.8 \%)$ of 10,708 cases of total PMFBDOs were due to bacteria: Campylobacter spp. (27,0\%), Salmonella spp. (25.6\%), Vibrio parahaemolyticus $(18.1 \%)$, E. coli $(7.3 \%)$, Staphylococcus aureus $(4.0 \%)$, Bacillus cereus $(0.7 \%)$, Yersinia entelocolitica $(0.2 \%)$ and other species $(1.0 \%)$. PMFBDOs caused by virus were 1,461 $(13.7 \%)$ : SRSV $(13.6 \%)$ and others $(0.1 \%)$, respectively. The PMFBDOs attributed to Salmonella spp., Staphylococcus aureus and Vibrio parahaemolyticus were more frequent in Korea than in Japan $\left(\mathrm{X}^{2}\right.$ test; $\mathrm{p}<0.01$ ), even though Campylobacter spp. and Salmonella spp. were the main causes in Japan as well. The PMFBDOs attributed to Campylobacter spp. and SRSV were more common in Japan $\left(\mathrm{X}^{2}-\right.$ test; $\mathrm{p}<0.01$ ).

Table 2. Comparative observation of foodborne disease outbreaks in venues between Korea and Japan from 1999 to 2004

\begin{tabular}{lcccc}
\hline \hline \multicolumn{2}{c}{ KOREA } & \multicolumn{2}{c}{ JAPAN } \\
\multicolumn{1}{c}{$\begin{array}{c}\text { No. of } \\
\text { Venues }\end{array}$} & Outbreaks (\%) & $95 \% \mathrm{Cl}^{\sharp}$ & Outbreaks (\%) & $95 \% \mathrm{Cl}^{*}$ \\
\hline Home & $64(8.6)$ & $6.6-10.6$ & $1,448(12.1)^{* *}$ & $13.9-15.1$ \\
Restaurant & $240(32.0)^{* *}$ & $28.7-35.4$ & $2,836(23.7)$ & $22.9-24.5$ \\
Hotel/inn & $7(0.9)$ & - & $628(5.3)^{* *}$ & $4.9-5.7$ \\
School & $206(27.5)^{* *}$ & $28.9-29.1$ & $158(1.3)$ & $1.1-1.5$ \\
Work place & $57(7.6)^{* *}$ & $5.7-9.5$ & $348(2.9)$ & $2.6-3.2$ \\
Other's & $159(21.2)^{* *}$ & $18.4-24.1$ & $781(6.5)$ & $6.1-7.0$ \\
Unknown & $16(2.1)$ & $2.0-3.2$ & $5,77(448.2)^{* *}$ & $47.3-49.1$ \\
Total & 749 & & 11,973 & \\
\hline
\end{tabular}

Remarks; Chi-squared analysis indicated a significant difference from the total value, ${ }^{*} \mathrm{p}<0.05,{ }^{*} \mathrm{p}<0.01$. \# 95\% CI: confidence interval of $95 \%$ of the Rate. 
Table 3. Comparative observation of the cause of microbial foodborne disease outbreaks between Korea and Japan from 1999 to 2004

\begin{tabular}{|c|c|c|c|c|}
\hline \multirow[b]{2}{*}{ Microbial agent } & \multicolumn{2}{|c|}{ KOREA } & \multicolumn{2}{|c|}{ JAPAN } \\
\hline & $\begin{array}{c}\text { No. of } \\
\text { Outbreaks }(\%)\end{array}$ & $95 \% \mathrm{Cl}^{\#}$ & $\begin{array}{c}\text { No. of } \\
\text { Outbreaks (\%) }\end{array}$ & $95 \% \mathrm{CI}^{*}$ \\
\hline \multicolumn{5}{|l|}{$\overline{\text { BACTERIA }}$} \\
\hline Bacillus cereus & $6(1.35)$ & - & $74(0.69)$ & - \\
\hline Campylobacter spp. & $6(1.35)$ & - & $2,886(26.95)^{* *}$ & $26.1-27.8$ \\
\hline Clost. botulinum & & - & $3(0.03)$ & - \\
\hline Clost. perfringenusm & $5(1.12)$ & - & & - \\
\hline Clost. welchii & & - & $175(1.63)$ & - \\
\hline E. coli & $28(6.28)$ & $4.0-8.5$ & $785(7.33)$ & $6.8-7.8$ \\
\hline Enterohemorrhagic E. coli & $5(1.12)$ & & $91(0.85)$ & - \\
\hline Salmonella spp. & $151(33.86)^{* *}$ & $31.2-37.7$ & $2,744(25.63)$ & $24.8-26.5$ \\
\hline Staphy. aureus & $62(13.90)^{* *}$ & $10.7-17.1$ & $432(4.03)$ & $3.7-4.4$ \\
\hline Vibrio parahe. & $121(27.13)^{* *}$ & $23.0-31.3$ & $1,938(18.10)$ & $17.4-18.8$ \\
\hline Yersinia entero. & & & $16(0.15)$ & - \\
\hline Others & $28(6.28)$ & $4.0-8.5$ & $103(0.96)$ & - \\
\hline Sum & $412(92.38$ & $89.8-94.8$ & $9,247(86.36)$ & $85.7-87.0$ \\
\hline \multicolumn{5}{|l|}{ VIRUS } \\
\hline Norovirus & $24(5.38)$ & $3.3-7.5$ & & \\
\hline SRSV & $5(1.12)$ & & $1,453(13.57)^{* *}$ & $12.9-14.2$ \\
\hline Calicivirus & $3(0.67)$ & & & \\
\hline Astrovinus & $2(0.45)$ & & & \\
\hline Others & $8(0.08)$ & & & \\
\hline Sum & $34(7.62)$ & $5.2-10.1$ & $1,461(13.64)^{* * *}$ & $13.0-14.4$ \\
\hline Total & $446(100 \%)$ & & $10.708(100 \%)$ & \\
\hline
\end{tabular}

Remarks; Chi-squared analysis indicated a significant difference from the total value, $* \mathrm{p}<0.05, * * \mathrm{p}<0.01$. \# 95\% CI: confidence interval of $95 \%$ of the rate.

\section{Discussion}

The FBDs are usually focused on by the general public who are expecting to explain rapidly both the causes of disease and its growth. ${ }^{10)}$ Greater numbers of people go out and eat meals prepared in foods facilities. In many countries, the boom in food service establishments is not matched by effective food safety and control. Insanitary preparation of food provides ample opportunities for contamination, growth, or survival of foodborne pathogens. ${ }^{2,11)}$

This study presents the results of the comparative observation on the FBDs between Korea and Japan. As shown Table 1, the prevalence rate of FBD was higher in Japan, while the cases per FBDs were more in Korea. One may explain the great differences of prevalence of FBD between two countries are based on the difference in their food handling and its cultural background, even tough these two countries are geographically located in close proximity. For example, compared to the Japanese, Koreans like their food spicier or saltier as well as fermented food such as a kimch, suggesting that perhaps the spicy or salty and fermented foods may damage pathogenic bacteria., ${ }^{5,12)}$

It is well known that most communicable disease are affected by season or climatic conditions. ${ }^{13)}$ Therefore, observation of the seasonal pattern of FBDs prevalence in both Korea and Japan. The distribution of FBDs throughout a year show a high incidence between the months of May, late in 
the spring, and June, early in the summer, but the prevalence declined from November to February, which are winter months in Korea (Table 1). On the other hand, peaks of FBDs existed between July and September in Japan. These data strongly indicate that the FBDs incidence in these two countries are influenced by their peculiar climate conditions, frequencies of national holidays, a school term (term-end holidays) and vacation, as well as the seasonal patterns of microbial infection. ${ }^{5,14)}$

The major venues of facilities where foods were improperly handled were homes and public consumptions such as restaurants, hotels, schools workplace and others including food stores and street food vendors (Table 2). In Korea, outbreaks of FBDs were frequently occurred via restaurants $(32.0 \%)$ and school foods $(27.5 \%)$, respectively, while via unknown venues $(48.2 \%)$, restaurants $(23.7 \%)$ and homes $(12.1 \%)$ in Japan. FBD outbreaks in restaurant were much higher in Korea than in Japan, whereas FBD outbreaks at homes were more frequent in Japan than in Korea. Recently in Korea, greater number of people go out and eat meals prepared in foods facilities, which are restaurants for their party, such as wedding or birth-day, and picnics, canteens, fast food outlets, and by street food vendors.

The global incidence of FBD is difficult to estimate, but it has been reported that in 2000 alone 2.1 million people died from diarrhea diseases. ${ }^{3)}$ A great proportion of these cases was attributed to contamination of foods and drinking water. ${ }^{3,15)}$ In order to understand the characteristics of Korean and Japanese FBDs, it is necessary to identify the state of food-related pathogenesis ${ }^{16}$. As shown in Table 3, bacteria were the major causes of infection in both countries. The PMFBDOs by Salmonella spp, Vibrio parahemolyticus and Stapphylococcus aureus were more frequent in Korea, while those by Campylobacter spp. and SRVS were more common in Japan. Michino and Otsuki ${ }^{17)}$ also reported that major hazards in 269 PMFBDOs in Japan were caused by Campylobacter jejini, Salmonella spp., E. coli and Staphylococcus aureus. In contrast, in the western hemisphere and in Europe, Salmonella serotype enteritis (SE) was the predominant strain, which was supposed to be largely related to the consumption of poultry eggs. ${ }^{2)}$

In oder to prevent PMFBDOs, it is necessary to avoid the contamination of foodstuff and to adopt proper measures of decontamination. It is also essential that the public health sector. collaborate with the agriculture and fisheries sectors. ${ }^{5,18)}$ Actually, our lives are becoming increasingly dependent on safety of food supplies. The efforts including public health vigilance, careful investigation of new problems, responsible attention of food safety from to table, and partnership to bring about new FBD control measurement will be tools for achieving improved future..$^{14,19-22)}$ Moreover, it requires refinements with appropriate distributions and mechanical relationships before it can be applied to a specific pathogen-food-consumer situation. ${ }^{5)}$ Therefore, further studies are needed to investigate the association of the epidemiological aspects between Korea and Japan.

Finally, outbreaks of FBDs in Korea and Japan for the purpose of achieving this goal, microbiological criteria should be update for many varieties of foods. Also, the prevention and reduction of biological and chemical contamination of foods should be regularly achieved by the public health food sanitation authorities.

In conclusion, The prevalence of FBDs in Korea and Japan showed characteristic differences. Especially, the PMFBDOs in Korea and Japan. These results reflect cultural, food habit, handling and foodstuff, climate and geographical differences between two countries.

\section{References}

1. World Health Organization (WHO) : Food Safety and Foodborne Illness. Fact Sheets $\mathrm{N}^{\circ}$ 237, 2002, www.who.int/inf-fs/en/fact 237.html.

2. World Health Organization (WHO) : Emerging Foodborne Diseases. Fact Sheets $\mathrm{N}^{\circ} 124,2002$, www.who.int/inf-fs/en/fact 124.html.

3. Bender, J.B., Smith, K.E., Hedberg, C. and Osterholm, M.T. : Foodborne disease in 21 st century. What challenges await us. Journal of Postgrad Medicine, 106, 109-112, 1999.

4. Kaferstein, F. and Abdussalam, M. : Food safety in the 21 st century. Bulletin of World Health Organization (WHO). 77, 347-351, 1999.

5. Lee, W.C., Lee, M.J., Kim, J.S. and Park, S.Y. : Foodborne Illness Outbreaks in Korea and Japan Studied Retrospectively. Journal of Food Protec- 
tion, 64, 899-902, 2001.

6. Korea Food and Administration (KFDA) : "Outbreaks Food Poisoning", Korea Food and Administration, 1999-2004. (http://www.kfda.go.kr/).

7. Korea Food and Administration (KFDA) : "Status of Food Poisoning Outbreaks", Korea Food and Administration. 1999-2004.

8. Ministry of Health, Labour and Welfare, Japan (MHLWJ) : "Topics; Food Safety Information; Annual Report of Food Poisoning Outbreaks" (Web), Ministry of Health, Labour and Welfare, Japan. 1999-2004. (http://www.mhlw.go.jp/topics/ syokuchu/index.html)

9. Ministry of Health, Labour and Welfare, Japan (MHLWJ) : "Statistics of Food Poisoning Japan", Ministry of Health, Labour and Welfare, Japan 1999-2004.

10. Cekanac, R., Cobeljic, M. and Opacic, D. : Foodborne disease outbreak among soldiers in Nisgarrison associated with the consumption of coleslaw. Vojnosanteteski Pregled, 63, 564-568, 2006.

11. Jung, H.K. : Ecological studies on the causative agents of food poisoning from food animals. Korean Journal of Environmental Health, 28, 9098, 1994.

12. Tsi, Y.A. and Inham, S.C. : Survival of Escherichia coli $0157: \mathrm{H} 7$ and Salmonella spp. in acidic condiments. Journal of Food Protection, 60, 751-755, 1997.

13. Hal, G.V., D'Souza, R.M. and Kirk, M.D. : Foodborne disease in the new millennium: out of the frying pan and into the fire. The Medical Journal of Australia, 177, 614-618, 2002.

14. Tauxe, R.V. : Emerging foodborne pathogens. International Journal of Food Microbiology, 15, 31-41, 2002

15. Lee, D.G. : Safety investigation of tap water and biofilm by isolated bacteria. Korean Journal of Environmental Health, 30, 207-213, 2004.

16. Batz, M.B., Doyle, M.P., Morris, Jr J.G., Painter, J., Singh, R., Tauxe, R.V., Taylor, M.R. and Lo Fo Wong, M.A. : Attributing illness to food. Emerging Infectious Diseases, (Center for Disease Control and Prevention) 11, 993-999, 2005.

17. Michino, H. and Otsuk, K. : Risk factors in causing outbreaks of foodborne illness originating in schoollunch facilities in Japan. The Journal of Veterinary Medical Science, 62, 557-560, 2000.

18. Lipp, E.K. and Rose, J.B. : The role of seafood in foodborne disease in the United States of America. Revue Scientifique et Technique (International Office of Epizootics), 16, 620-640, 1997.

19. Widdowson, M.A., Sulka, A., Bluens, S.N., Bward, R.S., Chaves, S.S., Hammond, R., Salehi, E.D., Swanson, E., Totaro, J., Woron, R., Mead, P.S., Bresee, J.S., Monroe, S.S. and Glass, R.I. : Norovirus and foodborne dosease, United States, 19912000. Emerging Infectious Diseases (Center for Disease Control and Prevention), 11, 95-102, 2005.

20. McNab, W.B. : A general framework illustrating an approach to quantitative microbial food safety risk assessment. Journal of Food Protection, 61, 1212$1228,1998$.

21. Kim, J.G. : Studies on the food hygiene \& safety knowledge, attitudes, and practice of kitchen employees in school food-service programs-part 1. Korean Journal of Environmental Health, 30, 173183, 2004.

22. Mead, P.S., Slutsker, L., Dietz, V., McCagi, L.F., Bresee, J.S., Shapiro, C., Griffin, P.M. and Tauxe, R.V. : Food-related illness and death in the United States. Emerging Infectious Diseases, (Center for Disease Control and Prevention), 5, 607-625, 1999. 